\title{
Dementia caregiving in spousal relationships: A dyadic perspective
}

\author{
Melanie Braun ${ }^{a *}$, Urte Scholz ${ }^{a}$, Barbara Bailey ${ }^{b}$, \\ Sonja Perren ${ }^{c}$, Rainer Hornung ${ }^{\text {a }}$ and Mike Martin ${ }^{\text {a }}$ \\ a Department of Psychology, University of Zurich, Zurich, Switzerland; \\ ${ }^{b}$ Psychiatric University Hospital Basel, Basel, Switzerland; \\ cJacobs Center for Productive Youth Development, University of Zurich, Zurich, Switzerland
}

\begin{abstract}
Objectives: The number of couples facing a dementia diagnosis for one partner of the spousal dyad increases. Spousal caregiving can be a highly stressful experience associated with negative caregiver outcomes such as depression and poorer immune function. However, surprisingly little is known about how the illness and the required care effects patient's well-being and relational changes experienced by afflicted couples. The aim of this study was to provide a literature review on how the dyadic perspective is taken into account and on how dementia effects both parts of the dyad.

Methods: In order to outline findings about individual and dyadic well-being of affected couples, we conducted a literature search to review the three types of studies. First, studies focusing on one partner's perspective, usually the perspective of the caregiver; second, studies including the caregiver's and partially the care receiver's view; third, studies directly referring to both partners' perspectives.

Results: The majority of studies neglect the individual with dementia by exclusively assessing caregiver variables or only indirectly including patients' characteristics. Very few studies embrace dyadic and relational variables to execute how both partners experience the illness, spousal caregiving, and changes in the relationship. Despite the arguable validity of self reports of individuals with dementia, some studies demonstrated the usefulness of including both partners' perspectives.

Discussion: Results indicate the urgent need of integrating the perspective of the individual with dementia to improve the understanding of the effects of dementia caregiving. Directly assessing the dyadic perspective of affected couples provides essential information for interventions.
\end{abstract}

Keywords: dementia care; spousal caregiving; dyadic perspective

\section{Introduction}

Due to increased life expectancy, a growing number of older couples have to face the transition to a caregiving relationship when one spouse becomes physically ill, frail, or develops dementia. Following this societal development, scientific dementia literature reveals growing interest in afflicted partners. However, research on dyadic variables and developments is rarely found. Thus, we consider it timely and necessary to review the existing caregiving literature with regard to what can currently be said about the impact of dementia on relationship dynamics, as well as on individual and dyadic well-being of afflicted couples. Furthermore, we aim to outline the main deficits of past research and demonstrate potential gains of dyadic studies indicating both partners' perspectives.

Dementia is a syndrome indicating brain and cognitive dysfunction causing significant impairment in social functioning (Bondi \& Lange, 1998). Since this article concentrates on the impact of dementia on dyadic processes, we do not discriminate in the following between different dementia forms when using the term dementia.
Due to growing impairments in the course of the illness, personal relationships of people who suffer from dementia, such as the relationship between the caregiver and the care recipient, may be negatively impacted. The provision of care for a spouse with dementia can be physically and mentally demanding and stressful. Consequently, many studies have demonstrated increased stress levels and other negative consequences for spousal caregivers' health and quality of life (e.g., Pinquart \& Soerensen, 2003; Vitaliano, Zhang, \& Scanlan, 2003). There are, however, also contrary results indicating differences between caregivers with respect to their adaptability to the caregiving situation (Alspaugh, Stephens, Townsend, Zarit, \& Greene, 1999; Danhauer et al., 2004; Gaugler, Davey, Pearlin, \& Zarit, 2000; Schulz \& Williamson, 1991). Nonetheless, the overall knowledge on the caregiver's mental and physical well-being is broad. In contrast, relatively little is known about how caregiver and care receiver variables interact. Taking both perspectives into account might not only help to explain some of the ambiguous findings on the caregiver side but also to get a better understanding

*Corresponding author. Email: Melanie.Braun@psychologie.uzh.ch 
of the changes and processes taking place within the dyad as dementia progresses.

\section{Aim of the review}

This article concentrates on the impact of dementia on the afflicted spousal dyad. It aims to review existing studies with regard to the amount of the integrated dyadic perspective. Thereby, we will illustrate methodological and theoretical discrepancies in dementia caregiver literature and offer suggestions for future dyadic dementia research that may overcome existing methodological problems.

\section{Methods \\ Categorization of caregiving research from a dyadic perspective}

A comprehensive computerized literature search with the terms 'dementia care* spous*', 'spousal/familial care*', 'dyad* dementia' was performed using the data bases PsycINFO and pubmed. Focusing on a dyadic perspective, studies on dementia caregiving can be categorized by the amount to which they take dyadic processes into account. Here, three data collection methods can be distinguished, as follows.

First, data about the caregiving situation are gathered from one person only, usually from the caregiver. This type of study design focuses only on variables from one individual indicating no dyadic perspective per se. The only data concerning the partner are typically the diagnosis, age, and gender. Although these factors are relevant, they do not include aspects of dyadic interactions.

Second, data are collected from both partners of the caregiving dyad, whereas one individual's perspective is directly and the partner's perspective is indirectly measured (e.g., by using caregiver information to assess care receiver variables or dyadic constructs).

Third, some studies include directly measured data from both partners. In this case, the dyadic perspective is adequately integrated in the analyses. Each of these data collection designs offers its advantages and disadvantages, which we will describe in the following sections.

\section{Results}

\section{Studies focusing on one part of the dyad: The caregiver's perspective - Overview}

The literature search revealed a high number of studies on spousal dementia caregiving by analyzing the perspective of the caregiver. For instance, the term 'dementia care* spous"' led to more than 270 items. Due to the high number of studies and our main focus on dyadic variables, we only describe some example studies exclusively assessing caregiver variables. Furthermore, comprehensive meta-analytic data giving a broad overview of the caregiver's situation (e.g., Pinquart \& Soerensen, 2003; Vitaliano et al., 2003) are recommended for interested readers.

Studies solely referring to caregiver features provide information on the impact of caregiving on the dementia caregiver's health and well-being. Negative outcomes associated with spousal caregiving are well documented in the research literature (Kiecolt-Glaser, Dura, Speicher, Trask, \& Glaser, 1991; Pinquart \& Soerensen, 2003; Schulz, O'Brien, Bookwala, \& Fleissner, 1995). Although carers averagely report high burden and low well-being, some caregivers manage to remain high in levels of satisfaction, mental, and physical health (e.g., Kramer, 2000; Townsend et al., 1989), and even report positive implications and gains (Kramer, 1997). Similarly, Heru, Ryan, and Iqbal (2004) examined spousal caregivers of moderately disabled subjects with dementia and found that caregivers perceived more reward than burden and their quality of life was similar to a control sample. These findings indicate that caregiving can be a rewarding experience, as well.

\section{Moderators of the association between caregiving and caregiver well-being: Gender and communication}

Variables that potentially moderate the relationship between caregiving and caregiver well-being have been considered in several studies. One important moderator is gender of the caregiver. Research shows that men seem to adapt better than women to the caregiving situation (Gilhooly, Sweeting, Whittick, \& McKee, 1994). In fact, Thompson et al. (2004) demonstrated key differences in physiological and emotional responses: male spousal caregivers had significantly lower levels of stress, depression, anxiety, subjective caregiver burden, anger-hostility, and somatic symptoms as well as higher levels of social and physical functioning, mental health, and sense of coherence compared with female caregivers. No gender differences were found in social support and coping resources. These male advantages were confirmed in a meta-analysis, which indirectly included patient's measurements (Pinquart \& Soerensen, 2006). However, the differences were small to very small. Nevertheless, the question how these biological and emotional responses of the caregivers are moderated by care receiver or dyadic features (e.g., relationship quality, social exchange within the dyad) remains unanswered.

Research on marital relationships has identified communication skills as main predictors of marital satisfaction and relationship quality (Weiss \& Heyman, 1997). It has been demonstrated that interaction and communication patterns are clearly related to marital happiness (Litzinger \& Gordon, 2005). It is plausible to assume that marital satisfaction and communication in dementia caregiving dyads are similarly related. Polk (2005) conducted interviews with spousal and familial 
caregivers to describe the role of communication in dementia caregiving. Results showed that caregivers are often confronted with uncertainty about dyadic interactions and about how to attribute reactions of their partners (e.g. when the patient is unable to verbally and unequivocally express pleasure or displeasure). Since the interviews only included the caregivers' perspectives, it is possible that the care receivers may not agree with the caregiver.

\section{Summary: Studies referring to the caregiver's perspective}

Studies focusing on caregiver measurements are economical and frugal to accomplish, but they contribute little information on dyadic interactions. Nevertheless, even from a dyadic perspective, these studies can provide relevant information because caregiver well-being could affect the care receiver. As an example, it is plausible to suggest that caregivers with poorer mental and physical health may have less effective coping strategies which in turn affect the care receiver (Hooker et al., 2002). In sum, study designs only including the carer's perspective may, from a dyadic view, at least give hints on relevant caregiver aspects which might influence the caregiving dyad. However, possible interactions between caregiver and care receiver features require more detailed dyadic information.

\section{Studies focusing on one part of the dyad: The perspective of individuals with dementia}

There are only few research projects that have directly involved individuals with dementia and thereby successfully demonstrated the usefulness of focusing on the care receiving partner. In a study by Clare (2002), individuals with early-stage dementia described their coping strategies and emotional responses following the growing dementia symptoms. Many participants were able to name various ways in which they tried to adjust to dementia symptoms (e.g., compensating strategies, developing a fighting spirit). Additionally, many participants reported to enjoy the feeling to be an important source of information for researchers despite their illness. Cotrell and Schulz (1993) summarized other benefits for patients, such as telling one's unique and unheard story, thus, participating in a study may contribute to the patients' self-esteem and well-being. The usefulness of including individuals with cognitive impairments in research studies can also be supported by a study in which dementia patients completed self report questionnaires to assess personality dimensions (e.g., dominance, cold heartedness, extraversion). For some dimensions, patients did not differ significantly from normal controls in their self awareness. They exhibited proper insight into many dimensions of personality and into personality changes (Rankin, Baldwin, Pace-Savitsky, Kramer, \& Miller, 2005).
These studies can be interpreted as important attempts to exhibit the patients' perspective, but miss to assess the caregiving partner's perceptions. Consequently, dyadic information cannot sufficiently be achieved from these studies. In other words, although, these studies demonstrated the opportunity to directly include individuals with dementia in research studies, the dyadic perspective is not sufficiently considered when the second part of the couple, either the caregiving or the care receiving partner, does not partake in these investigations. Studies actually referring to both partners are indeed the only possibility to get insight into caregiving dyads.

The near absence of the patient's perspective in dementia literature is probably due to ethical aspects, problems of studying this special population, and the questionable accuracy of demented subjects' statements (Cotrell \& Schulz, 1993). As individuals with dementia may demonstrate distractibility, concentration difficulties, or misunderstanding during assessment, they are often seen as unreliable respondents (Cotrell \& Schulz, 1993; Gilhooly et al., 1994). However, a better insight into relationships of afflicted couples is unapproachable when one half of the dyad is neglected.

\section{Indirect measurement of care receiver characteristics: Overview}

The majority of dementia caregiver studies examined the perspectives of subjects with dementia either by analyzing data of caregivers, or by observational methods of the dementia individual (e.g., observation of behavioral disturbances). Dementia severity and level of dementia symptoms are commonly assessed features. Although discrepancies between self-reports of individuals with dementia and proxy ratings of clinicians and caregivers are well documented (Gibbons, Teri, Logsdon, \& McCurry, 2006; Teri \& Wagner, 1991), these data are usually gained by proxy ratings.

\section{The importance of care receiver characteristics: Dementia severity, problematic behaviors, and neuropsychiatric symptoms}

The identification of factors that increase the risk of negative caregiver outcomes is generally useful in detecting particularly vulnerable caregivers. It is plausible that dementia severity is associated with caregiver well-being indicating that higher severity correlates with lower well-being; but this association could not unequivocally be demonstrated (Gilhooly et al., 1994). Indeed, the relation between dementia symptoms and caregiver well-being seems to be more complex. A study of Majerovitz (1995) examined that greater memory and behavioral problems were related to higher levels of spousal caregiver burden and depression. An extensive longitudinal intervention study with mainly spousal caregivers by Perren, 
Schmid, and Wettstein (2006) explored associations between the caregivers' well-being and the course of the demented persons' impairment. Results showed that level and increase in problematic behaviors (aggression, apathy, etc.) and increases in functional and cognitive deterioration of the care receiver negatively affected caregiver well-being. Thus, not only the severity of current problems and the stress the caregiver experiences, but also the rate of change is substantial for caregiver well-being.

Another association between caregiver characteristics and care receiver symptoms has been demonstrated by Sink, Covinsky, Barnes, Newcomer, and Yaffe (2006). They showed that caregiver characteristics (e.g. age, level of education, caregiver burden) are correlated with neuropsychiatric symptoms of the partner with dementia, independent of other patient characteristics. In this study, familial and spousal caregivers who were younger, more depressed, less educated, more burdened, or spent more hours caring reported more neuropsychiatric symptoms of the care receiver.

Referring to specific patient behaviors, DeVugt et al. (2003) indirectly included dyadic information by investigating the association between particular dementia symptoms and changes in the marital relationship. Both variables were assessed by caregiver-based measures. The results indicated that passive and apathic behavior of the care receiver had most impact on the deterioration of the marital relationship.

On the one hand, these studies demonstrated the interrelation between care receiver and caregiver characteristics, and on the other, they show the utility for taking care receiver features into account when predicting the behaviors and the well-being of individuals within a dyad.

\section{Caregiver appraisal of changes in the spousal relationship}

Some studies indicated both negative and positive psychosocial changes for dementia caring spouses. Gallagher-Thompson, Dal Canto, Jacob, and Thompson (2001) found that caring wives not only reported a lower well-being (e.g., depression, stress) than wives of healthy partners, but also noticed similar closeness and shared values to their husbands compared to noncaring wives. Eloniemi-Sulkava et al. (2002) conducted interviews with caregivers to examine the changes spousal carers experience after illness onset. The participants reported a significant decline in happiness. Additionally, the majority of caregivers (79\%) described the relation as an equal companionship before dementia onset, but less than one third of them $(29 \%)$ perceived the relationship as equal after illness onset. On the one hand, participants reported that many dimensions of the marriage were negatively influenced by dementia (e.g., disturbing jealousy of the care recipient). On the other, the illness did not significantly affect the general atmosphere of the relationship and a few carers even report positive changes (e.g., increased tenderness). Narayan, Lewis, Tornatore, Hepburn, and Corcoran-Perry (2001) confirmed the coexistence of negative and positive changes for caregiving spouses. For example, spouses reported experiencing caring as self-fulfilling and affirming while concurrently experiencing negative responses, such as relational deprivation with their partners. In terms of changes in the marital relationship, the majority of carers perceive a deterioration of their relationship, but at the same time, they report feeling closer to their spouses now than in the past (DeVugt et al., 2003). The fact that positive and negative relationship changes can coexist underlines the complex situation of spousal caregivers and their care receiving partners. Going back to the dyadic perspective, there is a lack of studies investigating how the relationship changes reported by the caregivers are experienced by the care receivers and what the associations with the care receiver's well-being are.

Sexual satisfaction and sexual activity might be two other factors influencing caregiver burden. As an example, Eloniemi-Sulkava et al. (2002) outlined the frequency of negative changes in afflicted couples' sexuality. In this study, the majority of caregivers declared that the dementia partners' expression of sexual needs decreased after dementia onset. The carers also perceived that the sexual marital relationship was less important in their spouses' life after illness onset and $60 \%$ of the caregiving participants experienced negative behavioral changes of their partners. Simonelli et al. (2008) reported higher burden in spousal dementia caregivers who had less sexual intercourse. They also demonstrated a gender-specific effect since male caregivers had more sexual intercourse than female carers. The patient's sexual satisfaction was not assessed in this study. Consequently, how the caregivers' and the care receivers' sexual needs and activities converge or diverge remains unclear.

There are a number of factors in the caregiving setting, such as relationship quality and affection, which helps to build or enhance caregiver resiliency. Horowitz and Shindelman (1983) demonstrated the relevance of affection between caregiver and care receiver. They presented a significant association between caregiver perceived affection and stress symptoms in spousal and familial carers: the more affection the caregiver felt for the care recipient, the less negatively caregiving demands were experienced. In this study, affective relationships were negatively influenced by the need to provide care, indicating a decrease of affective feelings. Conversely, other familial carers participating in this study showed a trend towards a closer emotional bond to the care recipient now than in the past. Since marital relationships were most negatively affected, the authors conclude that spousal relationships suffer the greatest strain as a result of caring. However, this raises the question how caregiver and care receiver perceived affection is 
related and how amount of concordance or disconcordance may affect the dyad. Knop, Bergman-Evans, and McCabe (1998) examined the association between relationship quality and depression in spouses caring for their partners with dementia. The results showed that past and present relationship quality was inversely linked to depression. The authors concluded that carers with good past and present relationship quality are more committed, less depressed, and more likely to find gratification in caring for their spouses. Nevertheless, the majority of participants rated the present relationship quality less favorably than past relationship quality. Similarly, Lawrence, Tennstedt, and Assmann (1998) found that higher relationship quality was associated with lower depression levels, even when controlled for disability and cognitive impairment of the care recipient. Another study focused on the caring spouse's perspective of the caregiving situation (Lewis, Hepburn, Narayan, \& Kirk, 2005). Higher well-being, lower burden, lower depression, and higher caregiver competence were found in spouses who described the caregiving relationship as being a continued spousal connection and integrated the caregiving role in the marital relationship. These spouses saw caring as part of the continued relationship with their partners. Taken together, good past and present relationship quality might help the spousal caregiver to adapt more effectively to the caregiving situation. Nevertheless, it remains unclear how the amount of agreement between both partners' perceived relationship quality influences dyadic well-being.

\section{Summary: Research indirectly including care receiver characteristics}

Within all these studies, patients' variables were assessed by caregiver-based measures. Thus, dyadic changes were detected for only one part of the dyad. Indeed, studies have demonstrated the importance of protective and risk factors, either of the caregiver or the care receiver (e.g., problem behaviors of the care receiver), or the dyad (e.g., relationship quality) influencing caregiver adaptability. However, the current state of research is unsatisfying since indirect measurements of the care receiver perspective provide only partial information about the dyad. No definite conclusions concerning the interaction between caregiver and care receiver factors can be drawn because the care receiver's view of the dyadic situation remains unexplained. Many studies demonstrated only low correlations between self-reports of dementia individuals and ratings from their caregivers (Carpenter, Kissel, \& Lee, 2007; Gibbons et al., 2006; Naglie et al., 2006; Teri \& Wagner, 1991) indicating that indirect measurements provide inaccurate information. Thus, assessments using proxies should be used with caution (Novella et al., 2006). Self reports of the care receivers are hardly found in the literature
(Cotrell \& Schulz, 1993). Hence, past research has not only neglected a resource for understanding some kind of inconsistency in the presentation and progression of the illness, but also personal and psychosocial needs, as well as experiences of dementia individuals have long been put aside (Nygard, 2006). One reason for this was the preference for proxy ratings rather than direct assessment of the care receiver variables due to the questionable validity of self ratings from individuals with cognitive deficits.

\section{The assessment of the dyadic perspective}

\section{Studies including the dyad: Combination of caregiver} and care receiver variables

The literature search revealed only a few studies directly including both partners of couples afflicted with dementia and spousal dementia caregiving, respectively. The most important studies using direct measurements of spousal dementia caregivers and their spouses are listed in historical order and briefly described in Table $1(N=5)$.

Wright (1991) examined level of congruency in caregiving and noncaregiving spouses' and their partners' perceptions of the martial relationship. Perceived marital quality, constituting of several factors (e.g. consensus, sexuality), of both partners was directly assessed. Caregivers and care receivers showed more incongruence than healthy couples in their perception of agreement over sexuality and tension. Additionally, caregivers were less sexually active $(27 \%)$ than their noncaring counterparts $(82 \%)$. On the one hand, this study demonstrates the problematic accuracy of self-reports of subjects with dementia. It remains unclear whether the reason for the higher incongruence in spouses with dementia is caused by cognitive impairments of the patients possibly leading to a bias in their self- reports or by other factors associated with dementia, dementia caregiving respectively. On the other, it clearly indicates essential information about afflicted couples by precisely describing the response behavior that seemed to be typical of individuals with dementia (e.g. individuals with dementia perceived marital quality higher and report more sexual activity than their caring partners). Furthermore, this comprehensive study includes not only self reported information from both partners of afflicted dyads, but also observational data concerning affectionate gestures between the partners. In general, the evaluation of the couple perspective via subjective and objective methods generates a comprehensive insight into the dyadic interplay.

Spousal interaction was assessed in an outstanding study by Gallagher-Thompson et al. (2001). The authors used observational methods to capture the dyadic interaction and to compare communication patterns between caregiving and noncaregiving dyads ( $N=54$ couples). Fundamental differences were found between caring and noncaring wives: first, 
Table 1. Characteristics of studies assessing dyadic variables of caregiver-care recipient couples $(N=5)$.

\begin{tabular}{|c|c|c|c|c|}
\hline Authors & Study aim & Particpants & Examples of measures & Most salient findings \\
\hline Wright (1991) & $\begin{array}{l}\text { Investigating the impact of } \\
\text { dementia caregiving on the } \\
\text { marital relationship. }\end{array}$ & $\begin{array}{l}N=47 \text { couples ( } n=30 \text { demen- } \\
\text { tia caregiver couples; } n=17 \\
\text { healthy couples). }\end{array}$ & $\begin{array}{l}\text { Caregiver: marital quality (e.g., } \\
\text { tension, sexuality) observation of } \\
\text { affectionate gestures. } \\
\text { Care receiver direct: marital quality. } \\
\text { Care receiver indirect: dementia } \\
\text { severity. }\end{array}$ & $\begin{array}{l}\text { There is some incongruence between } \\
\text { self reports of the partners. The } \\
\text { person with dementia perceived } \\
\text { total marital quality higher and } \\
\text { over reported sexual activities than } \\
\text { the caregiving spouse. }\end{array}$ \\
\hline $\begin{array}{l}\text { Gallagher-Thompson } \\
\text { et al. (2001) }\end{array}$ & $\begin{array}{l}\text { Assessment of spousal interac- } \\
\text { tion of dementia caregiving } \\
\text { and noncaregicing couples. }\end{array}$ & $\begin{array}{l}N=54 \text { couples ( } n=27 \text { couples } \\
\text { with the husband suffering } \\
\text { from dementia). }\end{array}$ & $\begin{array}{l}\text { Caregiver: depression, stress, couple } \\
\text { communication. } \\
\text { Care receiver direct: couple commu- } \\
\text { nication. } \\
\text { Care receiver indirect: dementia } \\
\text { severity. }\end{array}$ & $\begin{array}{l}\text { Certain aspects of spousal commu- } \\
\text { nication remain intact despite the } \\
\text { progressive course of dementia. }\end{array}$ \\
\hline Reilly et al. (2006) & $\begin{array}{l}\text { Assessing the validity of a self- } \\
\text { administered partner- } \\
\text { patient questionnaire for } \\
\text { shared activities. }\end{array}$ & $\begin{array}{l}N=100 \text { dyads ( } n=71 \text { spousal } \\
\text { dyads); analyses were sepa- } \\
\text { rated between spouses and } \\
\text { other familial dyads. }\end{array}$ & $\begin{array}{l}\text { Caregiver: Partner-patient } \\
\text { Questionnaire for Shared } \\
\text { Activities (PPQSA), work and } \\
\text { daily activity impairment. } \\
\text { Care receiver direct: disease insight, } \\
\text { depression. } \\
\text { Care receiver indirect: mood and } \\
\text { mental state assessed by proxy } \\
\text { ratings. }\end{array}$ & $\begin{array}{l}\text { Patient's depression was not related } \\
\text { to the PPQSA. Time spent care- } \\
\text { giving and caregiver burden were } \\
\text { related to the PPSQ. The PPSQ } \\
\text { assesses shared activities and seems } \\
\text { to be a valid proxy rating for } \\
\text { measuring illness severity. }\end{array}$ \\
\hline Perren et al. (2007) & $\begin{array}{l}\text { Longitudinal evaluation of the } \\
\text { impact of attachment style } \\
\text { on the patient's problem } \\
\text { behavior and the caregiver's } \\
\text { well-being. }\end{array}$ & $\begin{array}{l}N=116 \text { couples with one } \\
\text { spouse suffering from } \\
\text { dementia. }\end{array}$ & $\begin{array}{l}\text { Caregiver: attachment security, } \\
\text { avoidance and anxiety, emotional } \\
\text { well-being. } \\
\text { Care receiver direct: attachment } \\
\text { security. } \\
\text { Care receiver indirect: neuropsychia- } \\
\text { tric symptoms. }\end{array}$ & $\begin{array}{l}\text { The partners' attachment styles were } \\
\text { significantly associated. One third } \\
\text { of the patients were able to com- } \\
\text { plete the measurements. }\end{array}$ \\
\hline Searson et al. (2008) & $\begin{array}{l}\text { The evaluation of the impact of } \\
\text { activities enjoyed by demen- } \\
\text { tia patients together with } \\
\text { their partners on caregiver } \\
\text { well-being. }\end{array}$ & $\begin{array}{l}N=46 \text { couples with one spouse } \\
\text { suffering from dementia. }\end{array}$ & $\begin{array}{l}\text { Caregiver: mental health, Pleasant } \\
\text { Events Schedule - AD (PES-AD). } \\
\text { Care receiver direct: depression, } \\
\text { Pleasant Events Schedule - AD } \\
\text { (PES-AD). } \\
\text { Care receiver indirect: behavior } \\
\text { problems. }\end{array}$ & $\begin{array}{l}\text { Pleasurable activities enjoyed by both } \\
\text { partners are negatively correlated } \\
\text { with caregiver strain. Pleasurable } \\
\text { activities and behavioral problems } \\
\text { of the patients independently pre- } \\
\text { dict psychological morbidity in } \\
\text { caring spouses. }\end{array}$ \\
\hline
\end{tabular}

Note: Studies are listed in historical order. 
noncaregiving spouses were more interactive and expressed more support to each other compared with carer-care recipient spouses. Second, husbands with dementia were highest in interactions which build rapport (e.g., smiling). Due to the fact that GallagherThompson and colleagues used a cross-sectional study design, future research is needed to detect the development of spousal communication of afflicted couples. Furthermore, possible influencing factors such as depression levels or perceived relationship quality of both partners should be included in future studies.

To evaluate relationship dynamics, Reilly, Relkin, and Zbrozek (2006) developed a partner-patient questionnaire to measure interferences in the caregiver-patient relationship. They successfully included a self-reported depression scale and questions about disease insight of the partner with dementia. Analyses for spousal caregivers were conducted separately from other caregiving dyads indicating the problematic comparability of different caregiver subgroups. This is an advantageous methodological approach since past research repeatedly demonstrated significant differences between spousal and familial caregivers (e.g., Meuser \& Marwit, 2001). However, it would have been interesting to add measurements of the patient's answers to the partner-patient questionnaire and the partners' level of discrepancy and agreement, respectively.

A recent longitudinal study evaluated attachment styles of caregiving spouses and their partners $(N=116$ couples) (Perren, Schmid, Herrmann, \& Wettstein, 2007). The authors demonstrated not only that one third of the patients were able to complete the measures, but also a significant association between the spouses' attachment styles. Furthermore, insecure attachment styles of the spouse with dementia and avoidance attachment style of the caregiving partner were correlated with higher levels of dementia related problematic behaviours. In addition, results indicate both patients' problem behaviors and caregivers' attachment styles are related and that they directly influence caregiver well-being. It is an exemplary study because of its direct and longitudinal measurements of both partners.

Another high-quality study recently investigated whether activities enjoyed by both caregiving and care receiving spouse influence caregiver strain (Searson, Hendry, Ramachandran, Burns, \& Purandare, 2008). The authors included variables directly assessed in patients with mild dementia, such as depression and an instrument measuring activities enjoyed by the subject with dementia and their caregiver together. It constitutes of three subscales: one scale displays an 'ENJOY score' for care receivers on their own, one for caregiving spouses, and one for both care receiver and caregiver together. Results indicate first, that activities enjoyed by the spouses together are significantly related with caregiver well-being and second, that these enjoyed activities and patient's behavioral problems are independent predictors of caregiver's mental health. These findings strongly suggest the usefulness of supporting therapeutic dyadic strategies that involve caregiver and patient together.

\section{Summary: Problems and chances of including the dyadic perspective}

These studies actively involving both partners demonstrate that interviewing participants with dementia and interpreting patients' statements is certainly challenging but worth trying to improve our understanding of spousal dyads affected by dementia. In addition, several studies suggest that feasible qualitative data from demented subjects may be obtained at least in mild dementia (e.g. Carpenter et al., 2007; Sands, Ferreira, Stewart, Brod, \& Yaffe, 2004).

Several researchers have already mentioned the necessity of examining the dyadic perspective (Clare, 2002; Cotrell \& Schulz, 1993; Franks, Wendorf, Gonzalez, \& Ketterer, 2004; Gilhooly et al., 1994; Pearce, Clare, \& Pistrang, 2002). Hellström, Nolan, and Lundh (2005) criticized the fact that very few studies have focused on the relationship between caregiver and care receiver as well as on the way both partners experience this relationship. The authors conclude that the consideration of the 'couplehood' is essential to attain a better understanding of how spouses live with dementia. Lyons, Zarit, Sayer, and Whitlatch (2002) noted that 'the caregiving relationship, by definition, is made up of two people'. This implies that the understanding of how the partners' perspectives diverge and converge is relevant for research questions, theory building, and practical interventions.

\section{Potential moderators of dyadic processes in the caregiving setting: Overview}

Studies on caregiving differ not only in terms of the integrated dyadic perspective, but also in terms of using different samples, measurements, and study designs. This makes study comparisons questionable. In the following, we will discuss three problematic issues found in the literature possibly determining unsatisfying results.

\section{The need to separate caregiver subgroups}

Prevalence rates show that spouses are the predominant providers of long-term care for people suffering from dementia (e.g. Narayan et al., 2001). That raises the question whether familial caregiving dyads differ from spousal caregiving dyads. Indeed, the comparability of spousal and familial carers is problematic. Meuser and Marwit (2001) demonstrated differences in the quality of emotions reported by adult child and spouse carers. First, child caregivers basically described feelings of grief, anger, and frustration. Conversely, sadness was the predominant emotion in 
spouses constantly increasing from early to severe dementia stages of their partners. Second, spousal caregivers reported more empathy and compassion. Compared to adult child caregivers, caring spouses have a higher risk of physical health problems, depression, and role overload (Barnes, Given, \& Given, 1992), as well as higher stress levels and lower self-efficacy (Pinquart \& Soerensen, 2003). Despite these differences, many publications included spousal and familial caregivers in the same sample. Future studies need to differentiate between these caregiver subgroups in order to provide a clearer understanding of dynamics in the different carer-care recipient dyads.

\section{Considering the uniqueness of dementia caregiving}

The usual progressive course of dementia from mild forgetfulness to severe loss of cognitive function is rarely found in other diseases. Nevertheless, another methodological issue in caregiver research is that many studies do not differentiate between different care recipients' diagnoses suggesting that dementia caring can easily be compared with caring for individuals suffering from other chronic diseases. This, however, is problematic, as the demands in dementia care are usually different than in diseases without significant cognitive impairments. For example, Lee and Kolomer (2005) demonstrated that the severity of cognitive impairment correlates with the likelihood of severe problems within the dyad, such as abuse of a demented person by his familial caregiver. Another study displayed that nondementia caregivers experience lower stress levels than dementia caregivers (Bertrand, Fredman, \& Saczynski, 2006). However, since research findings are sparse, no solid answer can be given to the question whether dementia caregiving is generally more stressful and associated with qualitative different dyadic processes than caring for someone with another disorder (Gilhooly et al., 1994), but separate analyses of differing diagnostic groups are recommended.

\section{The need of theory-based research}

The last problematic aspect we want to discuss is that only few studies tried to generate and test theoretical explications for the impact of caring on caregivers and marital relationships. Some research projects are based on variations of the transactional theory of stress and coping from Lazarus and Folkman (1984; e.g., Lawton, Moss, Hoffman, \& Perkinson, 2000). This theory proposes that adaptation to stress is mediated by two variables: appraisal of the particular stress and the coping strategies of the individual. Referring to the caregiving situation, the adaptation hypothesis suggests that caregiving demands are strongest when caregiving begins. Due to the fact that the literature provides only partial support for this theory, the predictive usefulness of the adaptation hypothesis in dementia caregiving remains unclear (Kneebone \& Martin, 2003; Powers, Gallagher-Thompson, \& Kraemer, 2002). Moreover, here again, the focus lies exclusively on the caregiver but not on the afflicted dyad. In fact, this theory makes no predictions concerning the influences of social exchange and dyadic stress (Bodenmann, 2000). Only the integration of dyadic theories (e.g. Bodenmann's concept of dyadic stress, 2000) in a model will allow deriving hypotheses concerning caregiver stress and changes of the caregiving relationship.

Another theoretical construct, called family adaptability, considers dyadic variables to comprehend the relationship between caregivers and demented partners (Majerovitz, 1995). Family adaptability is one of the three dimensions constituting Olson's Circumplex Model (Olson, 2000), which describes differences between functional and less functional relationships. Family adaptability is defined as the amount of change in relationship leadership, role relationships, and relationship rules in response to situational needs. Olson suggested that couples with low levels of adaptability are less functional than couples with flexible and balanced family systems over time. Going back to spousal caregiving, Majerovitz (1995) demonstrated the relevance of family adaptability and showed that among less adaptable caregivers, greater illness-related stress correlates with greater depression; whereas this association was not found among more adaptable spouses. Less adaptable participants might have more difficulties in adjusting their daily routines in response to changing demands of dementia care (Majerovitz, 1995). Taken together, the concept of family adaptability seems to be a useful model concerning caregiver stress. However, empirical research that actually applied this model is rare.

Two social psychological theories provide relevant information to conceptualize dyadic relationships and are possibly useful to examine spousal caregiving (Baikie, 2002): Social Exchange Theory and Equity Theory (Walster, Walster, \& Berscheid, 1978b). The basic principles of Social Exchange Theory suggest that individuals try to achieve maximum rewards at minimum cost when they enter and remain in a relationship (K.J. Gergen \& M.M. Gergen, 1986). One important difference between these theories is that Equity Theory focuses on contributions to and obtainments from relationships. This theory assumes that the balance between what is given and what is received in an exchange is essential for the well-being of individuals (K.J. Gergen \& M.M. Gergen, 1986). Equity theorists believe that individuals who are confronted with inequity in their relationships will feel distress. Studies showed that equitable couples seem to be happier, more satisfied with their relationship, and more confident that the relationship will last than inequitable couples (Walster, Traupman, \& Walster, 1978a). However, rewards and costs may not always be balanced between two partners, but it is anticipated that equitable relationships may be 
balanced over time (Bierhoff \& Grau, 1999). We propose that these theoretical approaches can be fruitfully applied to caregiving couples. First, we assume that if the marriage is experienced as equitable for a long time before illness onset, the caregiving partner will positively interpret the duties of care as a reflection of the further relationship. Our assumption is linked to Baikie (2002), who proposed that caregiving spouses who experience their past relationship as good or equitable see the relationship as more positive and more equal. Thus, social exchange theories may illuminate why spouses provide care and why some caregivers even report positive aspects of caring for the spouse with dementia. Second, we anticipate that not only high quality, but also high equality of the past relationship enable the couple to maintain the relationship in times of illness (e.g., Knop et al., 1998; Lewis et al., 2005). Nevertheless, systematic studies have to be conducted in the future to assess the predictive usefulness of social exchange theories in the spousal caregiving context.

In sum, the lack of theoretical framework in dementia research in general and in dyadic processes in dementia research in particular, causes uncertainness as research findings often cannot be explained properly.

\section{Discussion and conclusions}

Taken together, this article demonstrates that dementia literature provides ambiguous results concerning the impact of caregiving for a partner with a dementing illness. Only a few studies actually refer to the spousal dyad indicating the integration of the caregiver's and the care receiver's view. Due to the fact that theorybased research is rather sparse, adequate theoretical explanations for the illustrated diversity in caregivers' outcomes cannot be given. Finally, we want to give recommendations on how to improve scientific knowledge of dyadic processes in couples afflicted by dementia.

First, dyadic data, such as interaction and social exchange, may be assessed using observational methods and self-reported data of both partners. Observational methods overcome possible limitations due to the cognitive decline in the individuals with dementia, but do not provide sufficient information. Thus, a combination of qualitative observations and interviews may be an effective method for demented study participants (Nygard, 2006).

Second, detailed studies separating between both different care receiver's diagnoses and different caregiver groups or that focus explicitly on one diagnosis and one caregiver group are needed to obtain better insight into dementia caregiving dyads. Implications from studies that do not divide spousal and familial caregivers, dementia caregivers and caregivers of individuals suffering from other diseases respectively, should be drawn cautiously. More detailed studies are needed to draw definite conclusions about dyadic processes in spousal dyads. Furthermore, we recommend longitudinal study designs to observe dyadic exchange processes and to investigate the development of potential adaptive resources during the illness progress.

Third, the examination of caregiving dyads should be based on a theoretical framework to enable theorybased explanations of the results and provide a basis for intervention strategies improving adaptive abilities for afflicted couples. As an implication for previous and future studies, we believe that applying theories appropriate for dyadic processes, such as the concept of dyadic stress (Bodenmann, 2000) or Equity Theory (Walster et al., 1978a, 1978b), will be an important step to expand our understanding of the diverse results in dementia research.

Due to the fact that first, spouses are the predominant care providers for individuals with dementia and second, the caregiving situation constitutes of a dyadic relationship between caregiver and care receiver, getting a better knowledge of the dementia caregiving dyad should be of great relevance for future research. Furthermore, focusing on the dyadic relationship will not only lead to a better comprehension of caregiver stress, but also helps to develop effective therapeutic interventions to enhance dyadic well-being of afflicted couples. Although integrating individuals with dementia into psychological studies will remain a difficult task in psychological and psychiatric research, some studies undoubtedly demonstrated its usefulness (e.g., Gallagher-Thompson et al., 2001). We expect that the advantages of direct assessments of both caregiver's and care receiver's perspectives will far outweigh the risks and disadvantages.

\section{References}

Alspaugh, M.E.L., Stephens, M.A.P., Townsend, A.L., Zarit, S.H., \& Greene, R. (1999). Longitudinal patterns of risk for depression in dementia caregivers: Objective and subjective primary stress as predictors. Psychology and Aging, 14(1), 34-43.

Baikie, E. (2002). The impact of dementia on marital relationships. Sexual and Relationship Therapy, 17(3), 289-299.

Barnes, C.L., Given, B.A., \& Given, C.W. (1992). Caregivers of elderly relatives: Spouses and adult children. Health and Social Work, 17(4), 282-289.

Bertrand, R.M., Fredman, L., \& Saczynski, J. (2006). Are all caregivers created equal? Stress in caregivers to adults with and without dementia. Journal of Aging and Health, 18(4), 534-551.

Bierhoff, H.W., \& Grau, I. (1999). Romantische Beziehungen (p. 106). Bern: Hans Huber.

Bodenmann, G. (2000). Stress und Coping bei Paaren. Göttingen: Hogrefe.

Bondi, M.W., \& Lange, K.L. (1998). Alzheimer's disease. Encyclopedia of Mental Health, 1, 65-82.

Carpenter, B.D., Kissel, E.C., \& Lee, M.M. (2007). Preferences and life evaluations of older adults with 
and without dementia: Reliability, stability, and proxy knowledge. Psychology and Aging, 22(3), 650-655.

Clare, L. (2002). We'll fight it as long as we can: Coping with the onset of Alzheimer's disease. Aging and Mental Health, $6,139-148$.

Cotrell, V., \& Schulz, R. (1993). The perspective of the patient with Alzheimer's disease: A neglected dimension of dementia research. The Gerontologist, 33(2), 205-211.

Danhauer, S.C., Beckett, L.A., McCann, J.J., Gilley, D.W., Bienias, J. L., \& Evans, D. A. (2004). Do behavioral disturbances in persons with Alzheimer's disease predict caregiver depression over time? Psychology and Aging, 19(1), 198-202.

DeVugt, M.E., Stevens, F., Aalten, P., Lousberg, R., Jaspers, N., Winkens, I., et al. (2003). Behavioural disturbances in dementia patients and quality of the marital relationship. International Journal of Geriatric Psychiatry, 18, 149-154.

Eloniemi-Sulkava, U., Notkola, I.L., Hamalainen, K., Rahkonen, T., Viramo, P., Hentinen, M., et al. (2002). Spouse caregivers' perceptions of influence of dementia on marriage. Intemational Psychogeriatrics, 14(1), 47-58.

Franks, M.M., Wendorf, C.A., Gonzalez, R., \& Ketterer, M. (2004). Aid and influence: Health-promoting exchanges of older married partners. Journal of Social and Personal Relationships, 21(4), 431-445.

Gallagher-Thompson, D., Dal Canto, P.G., Jacob, T., \& Thompson, L.W. (2001). A comparison of marital interaction patterns between couples in which the husband does or does not have Alzheimer's disease. The Journals of Gerontology Series B: Psychological Sciences and Social Sciences, 56(3), 140-150.

Gaugler, J.E., Davey, A., Pearlin, L.L., \& Zarit, S.H. (2000). Modeling caregiver adaptation over time: The longitudinal impact of behavior problems. Psychology and Aging, 15(3), 437-450.

Gergen, K.J., \& Gergen, M.M. (1986). Social psychology, (2nd ed.). New York: Springer.

Gibbons, L.E., Teri, L., Logsdon, R.G., \& McCurry, S.M. (2006). Assessment of anxiety in dementia: An investigation into the association of different methods of measurement. Journal of Geriatric Psychiatry and Neurology, 19(4), 202-208.

Gilhooly, M.L., Sweeting, H.N., Whittick, J.E., \& McKee, K. (1994). Family care of the dementing elderly. International Review of Psychiatry, 6, 29-40.

Hellström, I., Nolan, M., \& Lundh, U. (2005). We do things together. A case study of "couplehood" in dementia. Dementia, 4(1), 7-22.

Heru, A.M., Ryan, C.E., \& Iqbal, A. (2004). Family functioning in the caregivers of patients with dementia. International Journal of Geriatric Psychiatry, 19(6), 533-537.

Hooker, K., Bowman, S.R., Coehlo, D.P., Lim, S.R., Kaye, J., Guariglia, R., et al. (2002). Behavioral change in persons with dementia: Relationships with mental and physical health of caregivers. Journal of Gerontology: Psychological Sciences, 57(5), 453-460.

Horowitz, A., \& Shindelman, L. (1983). Reciprocity and affection: Past influences on current caregiving. Journal of Gerontological Social Work, 5(3), 5-21.

Kiecolt-Glaser, J.K., Dura, J.R., Speicher, C.E., Trask, O.J,, \& Glaser, R. (1991). Spousal caregivers of dementia victims: Longitudinal changes in immunity and health. Psychosomatic Medicine, 53, 345-362.
Kneebone, I., \& Martin, P. (2003). Coping and caregivers of people with dementia. British Joumal of Health psychology, 8, 1-17.

Knop, D.S., Bergman-Evans, B., \& McCabe, B.W. (1998). In sickness and in health: An exploration of the perceived quality of the marital relationship, coping, and depression in caregivers of spouses with Alzheimer's disease. Journal of Psychosocial Nursing and Mental Health Services, 36(1), 16-21.

Kramer, B.J. (1997). Gain in the caregiving experience: where are we? What next? The Gerontologist, 37(2), 218-232.

Kramer, B.J. (2000). Husbands caring for wives with dementia: A longitudinal study of continuity and change. Health and Social Work, 25, 97-107.

Lawrence, R.H., Tennstedt, S.L., \& Assmann, S.F. (1998). Quality of the caregiver-care recipient relationship: Does it offset negative consequences of caregiving for family caregivers? Psychology and Aging, 13(1), 150-158.

Lawton, M.P., Moss, M., Hoffman, C., \& Perkinson, M. (2000). Two transitions in daughters' caregivings careers. The Gerontologist, 40, 437-448.

Lazarus, R.S., \& Folkman, S. (1984). Stress, appraisal, and coping. New York: Springer.

Lee, M., \& Kolomer, S.R. (2005). Caregiver burden, dementia, and elder abuse in South Korea. Journal of Elder Abuse and Neglect, 17(1), 61-74.

Lewis, M.L., Hepburn, K., Narayan, S., \& Kirk, L.N. (2005). Relationship matters in dementia caregiving. American Journal of Alzheimer's Disease and Other Dementias, 20(6), 341-347.

Litzinger, S., \& Gordon, K.C. (2005). Exploring relationships among communication, sexual satisfaction, and marital satisfaction. Journal of Sex and Marital Therapy, 31, 409-424.

Lyons, K.S., Zarit, S.H., Sayer, A.G,, \& Whitlatch, C.J. (2002). Caregiving as a dyadic process: Perspectives from caregiver and receiver. The journals of Gerontology. Series B: Psychological Services and Social Sciences, 58(2), 112-128.

Majerovitz, S.D. (1995). Role of family adaptability in the psychological adjustment of spouse caregivers to patients with dementia. Psychology and Aging, I0(3), 447-457.

Meuser, T.M., \& Marwit, S.J. (2001). A comprehensive, stage-sensitive model of grief in dementia caregiving. The Gerontologist, 41(5), 658-700.

Naglie, G., Tomlinson, G., Tansey, C., Irvine, J., Ritvo, P., Black, S.E., et al. (2006). Utility-based quality of life measures in Alzheimer's disease. Quality of Life Research, 15(4), 631-643.

Narayan, S., Lewis, M., Tornatore, J., Hepburn, K., \& Corcoran-Perry, S. (2001). Subjective responses to caregiving for a spouse with dementia. Journal of Gerontological Nursing, 27(3), 19-28.

Novella, J.L., Boyer, F., Jochum, C., Jovenin, N., Morrone, I., Jolly, D., et al. (2006). Health status in patients with Alzheimer's disease: An investigation of inter-rater agreement. Quality of Life Research, 15(5), 811-819.

Nygard, L. (2006). How can we get access to the experiences of people with dementia? Suggestions and reflections. Scandinavian Journal of Occupational Therapy, 13(2), $101-112$. 
Olson, D.H. (2000). Circumplex model of marital and family systems. Journal of Family Therapy, 22(2), 144-167.

Pearce, A., Clare, L., \& Pistrang, N. (2002). Managing sense of self. Coping in the early stages of Alzheimer's disease. Denentia, l(2), 173-192.

Perren, S., Schmid, R., Herrmann, D., \& Wettstein, A. (2007). The impact of attachment on dementia-related problem behavior and spousal caregivers' well-being. Attachment \& Human Development, 9(2), 163-178.

Perren, S., Schmid, R., \& Wettstein, A. (2006). Caregivers' adaptation to change: The impact of increasing impairment of persons suffering from dementia on their caregiver's subjective well-being. Aging and Mental Health, 10, 539-548.

Polk, D.M. (2005). Communication and family caregiving for Alzheimer's dementia: Linking attributions and problematic integration. Health communication, 18(3), 257-273.

Powers, D.V., Gallagher-Thompson, D., \& Kraemer, H.C. (2002). Coping and depression in Alzheimer's caregivers: Longitudinal evidence of stability. The Journals of Gerontology Series B: Psychological Sciences and Social Sciences, 57, 205-211.

Pinquart, M., \& Soerensen, S. (2003). Associations of stressors and uplifts of caregiving with caregiver burden and depressive mood: A meta-analysis. Journals of Gerontology: Series B: Psychological Sciences and Social Sciences, 58(2), 112-128.

Pinquart, M., \& Soerensen, S. (2006). Gender differences in caregiver stressors, social resources, and health: An updated meta-analysis. The Journals of Gerontology Series B: Psychological Sciences and Social Sciences, 6I, 33-45.

Rankin, K.P., Baldwin, E., Pace-Savitsky, C., Kramer, J.H., \& Miller, B.L. (2005). Self awareness and personality change in dementia. Journal of Neurology, Neurosurgery and Psychiatry, 76, 632-639.

Reilly, M.C., Relkin, N.R., \& Zbrozek, A.S. (2006). Development and testing of a new outcome measure of relationship between patients with Alzheimer's disease and their partners. American Journal of Alzheimer's Disease \& Other Dementias, 2l(4), 249-257.

Sands, L.P., Ferreira, P., Stewart, A.L., Brod, M., \& Yaffe, K. (2004). What explains differences between dementia patients' and their caregivers' ratings of patients' quality of life? American Journal of Geriatric Psychiatry, 12, 272-280.
Schulz, R., \& Williamson, G.M. (1991). A 2-year longitudinal study of depression among Alzheimer's caregivers. Psychology and Aging, 6(4), 569-578.

Schulz, R., O'Brien, A.T., Bookwala, J., \& Fleissner, K. (1995). Psychiatric and physical morbidity effects of dementia caregiving: Prevalence, correlates, and causes. The Gerontologist, 35(6), 771-791.

Searson, R., Hendry, A.M., Ramachandran, R., Burns, A., \& Purandare, N. (2008). Activities enjoyed by patients with dementia enjoyed with their spouses and psychological morbidity in carers. Aging and Mental Health, 12(2), 276-282.

Simonelli, C., Tripodi, F., Rossi, R., Fabrizi, A., Lembo, D., Cosmi, V., et al. (2008). The influence of caregiver burden on sexual intimacy and marital satisfaction in couples with an Alzheimer spouse. International Joumal of Clinical Practice, 62(1), 47-52.

Sink, K.M., Covinsky, K.E., Barnes, D.E., Newcomer, R.J., \& Yaffe, K. (2006). Caregiver characteristics are associated with neuropsychiatric symptoms of dementia. Journal of the American Geriatrics Society, 54(5), 796-803.

Teri, L., \& Wagner, A.W. (1991). Assessment of depression in patients with Alzheimer's disease: Concordance among informants. Psychology and Aging, 6(2), 280-285.

Thompson, R.L., Lewis, S.L., Murphy, M.R., Hale, J.M., Blackwell, P.H., Acton, G.J., et al. (2004). Are there sex differences in emotional and biological responses in spousal caregivers of patients with Alzheimer's disease? Biological Research for Nursing, 5(4), 319-330.

Townsend, A., Noelker, L., Deimling, G., \& Bass, D. (1989). Longitudinal impact of interhousehold caregiving on adult children's mental health. Psychology and Aging, 4, 393-401.

Vitaliano, P.P., Zhang, J., \& Scanlan, J.M. (2003). Is caregiving hazardous to one's physical health? A metaanalysis. Psychological Bulletin, 129(6), 946-972.

Walster, E., Traupmann, J., \& Walster, G.W. (1978a). Equity and extramarital sexuality. Archives of Sexual Behavior, $7(2), 127-142$

Walster, E., Walster, G.W., \& Berscheid, E. (1978b). Equity: Theory and research. Boston: Allyn and Bacon.

Weiss, R.L., \& Heyman, R.E. (1997). A clinical overview of couples interactions. In W.K. Halford, \& H.J. Markman (Eds.), Clinical handbook of marriage and couples interventions (pp. 13-41). New York: Wiley \& Sons.

Wright, L.K. (1991). The impact of Alzheimer's disease on the marital relationship. The Gerontologist, 31(2), 224-237. 